\title{
The semantic component 'scale' in the meaning of a discourse particle uzh
}

\author{
Irina Levontina \\ Russian Language Institute RAS \\ irina.levontina@mail.ru
}

\begin{abstract}
The modal particle $u z h$ is perhaps the most difficult Russian discourse word to describe since its semantics is highly elusive. The existing descriptions are rather abstract and poorly correlate with various cases of usage of $u z h$. Besides, they do not take into consideration several crucial components of this particle's meaning. For instance, in phrases like Uzh ya-to znayu ('I do know') one can notice a hugely important component of meaning - the idea of a scale. One can say Ya-to etot sekret znayu, a vot drugim nevdomek ('I do know the secret, whereas others have no idea about it'), and in this example, uzh would be irrelevant. Uzh ya-to eto znayu presupposes that others probably know it too, but it's me who knows it for sure. This very idea of a scale and poles together with the idea of the exceedance of expectations (which is also important for the meaning of $u z h$ ) constitutes the semantic contribution that this particle makes. Moreover, $u z h$ partly smooths the opposition between the central and other elements of a multitude, because it does not exclude them from consideration, it just gives emphasis to that one.

The aim of this research is to examine those types of $u z h$ usage, where the idea of a scale is most clearly actualized. Probably, if we understand how the significant components of this particle's meaning function, we will get closer to the development of a complete picture of its usage. For example, the idea of a scale within the meaning of $u z h$ is expressed in the context of a special question (Zachem uzh tak zlo? 'Why so mean?'). In an argument uzh often implies that the speaker was almost ready to back down, but not to this extent - like in a famous poem by Daniil Kharms called «Liar» (1930). The idea of a scale is vividly realized in the context of an implicit (Gde uzh mne!, 'How can I...') or explicit negation. It is especially interesting to pay attention to the peculiar effects of the combination of uzh with comparative forms (luchshe uzh, 'it would be better...'). The usage of $u z h$ in standard word combinations raz uzh, esli uzh, togda uzh has its restrictions, also connected with the idea of a scale. The development of a modal meaning in a temporal word, which brings the transformation of a timeline into a scale of expectations or possibilities, is quite typical.
\end{abstract}

Keywords: Particles; discourse; Russian Language; scale

DOI: $10.28995 / 2075-7182-2021-20-473-482$

\section{Семантический компонент 'шкала' в значении дискурсивной частицы ужс}

\author{
И. Б. Левонтина \\ Институт русского языка им. В. В. \\ Виноградова РАН \\ irina.levontina@mail.ru
}

\begin{abstract}
Аннотация
Модальная частица уж, возможно, самое трудное для описания дискурсивное слово русского языка с плохо уловимой семантикой. Существующие очень абстрактные толкования с трудом соотносятся с разнообразными употреблениями уж. Кроме того, в них не вполне учтены некоторые существенные компоненты значения этой частицы. Так, во фразах типа Уж я-то знаю хорошо заметна чрезвычайно важная часть значения уж - идея шкалы. Можно сказать: Я-то этот секрет знаю, а вот другим невдомек, но уж было бы в этом случае неуместно. Уж я-то это знаю предполагает, что другие, возможно, знают тоже, но обо мне это можно сказать совершенно точно. Именно эта идея шкалы и полюса и составляет, в сочетании с идеей превышения ожиданий, также чрезвычайно важной для значения уж, собственный вклад частицы. Более того, уж даже
\end{abstract}


отчасти гасит противопоставление, поскольку оно показывает, что остальные элементы множества не исключаются из рассмотрения, а просто данный элемент оказывается особо выделен. Задача настоящей работы рассмотреть несколько типов контекстов употребления уж, в которых идея шкалы реализуется наиболее ярко. Возможно, если мы поймем, как работают важные компоненты смысла частицы, это приблизит нас к построению целостной картины ее функционирования. Так, идея шкалы в значении уж проявляется в контексте специального вопроса (Зачем уж так зло?). В споре уж часто выражает идею, что говорящий готов был бы пойти на уступки, но не до такой степени - как в знаменитом стихотворении Д. Хармса «Врун» (1930). Идея шкалы ярко реализуется в контексте имплицитного (Где уж мне!) или эксплицитного отрицания. Особенно интересно обратить внимание на своеобразные эффекты сочетания уж с компаративом (лучще уж). В типичных сочетаниях раз уж, если уж, тогда уж использование частицы имеет определенные семантические ограничения, также связанными с идеей шкалы. Развитие у временно́го слова модального значения, при котором происходит трансформация временно́й шкалы в шкалу ожиданий или возможностей, вполне типично.

Ключевые слова: частицы, дискурс, русский язык, шкала

\section{0.}

Модальная частица $\varkappa^{1}$, возможно, самое трудное для описания дискурсивное слово русского языка. Не случайно Е. В. Урысон характеризует модальное уж как «особое разговорное словечко с почти неуловимой семантикой, некий "наполнитель" высказывания, придающий ему идиоматичную разговорную окраску» [Урысон 2007: 539]. Эту частицу неоднократно исследовали, ей даже специально посвящено некоторое количество работ [Paillard 1986-87, Mendoza 1999, 2000, Урысон 2007, Левонтина 2008]. Довольно подробное перечисление контекстов употреблений частицы уж содержится в таких словарях, как «Словарь структурных слов русского языка» [Морковкин 1997], «Словарь русских частиц» [Шимчук, Щур 1999].

В работе Д. Пайара «Уж, или необсуждаемое» [Paillard 1986-87] предлагается толкование уж, смысл которого таков: уж маркирует некоторую ценность р как не подлежащую обсуждению и одновременно противопоставляет ее ценности р', которая эксплицитно или имплицитно задана в предшествующем контексте, однако в качестве преодоленной, отвергаемой, недействительной. Это, как и другие толкования инварианта уж, ориентировано в первую очередь на тот круг контекстов уж, который в словарях обычно рассматривается как реализация первого из его модальных значений (Уж я-то знаю). В словаре [Шимчук, Щур 1999] уж здесь толкуется в том смысле, что оно «выделяет из некоторого множества предмет, признак или событие, которые в ситуации выбора по тем или иным причинам должны быть рассмотрены в первую очередь».

Сходно с пайаровским толкование Цыбатова [Zybatow 1990]: уж указывает на выраженную в левом контексте или выводимую неуверенность в том, что входящее в сферу действия частицы утверждение соответствует действительности и подчеркивает, что оно не может не соответствовать действительности. На эту же тему - толкование И. Мендосы [Mendoza 2000]:

ужс

(a) маркирует какую-то ценность $\mathrm{W}$ как действительную;

(b) причем имплицируется также ценность $\mathrm{W}^{\prime}$, которая недействительна;

(c) причем ценность $\mathrm{W}^{\prime}$ имплицитно или эксплицитно фигурирует с предшествующем тексте или может быть выведена.

Как было показано в [Левонтина 2008], эти очень абстрактные толкования с трудом соотносятся с чрезвычайно разнообразными употреблениями уж. Кроме того, в них не вполне учтены некоторые существенные компоненты значения этой частицы. Так, в работе отмечалось, что в фразах типа Уж я-то знаю хорошо заметна чрезвычайно важная, на наш взгляд, часть значения уж - идея шкалы. Можно сказать: Я-то этот секрет знаю, а вот другим невдомек, но уж было бы в этом случае неуместно. Уж я-то это знаю предполагает, что другие, возможно, знают тоже, но обо мне это можно сказать совершенно точно. Именно эта идея шкалы и полюса и составляет, в сочетании с идеей превышения ожиданий, также чрезвычайно важной для значения уж, собственный вклад частицы в значение высказывания, в то время как идея противопоставления (ср. толкование Пайара), скорее всего, наводится контекстом. Более того, уж даже отчасти гасит противопоставление, поскольку оно показывает, что остальные элементы множества не исключаются из рассмотрения, а просто данный элемент оказывается особо выделен ${ }^{2}$.

\footnotetext{
${ }^{1}$ Временно́е уж как вариант или синоним уже здесь не рассматривается.

2 Отчасти это соотносится с компонентом 'в первую очередь' в дескрипции Шимчук и Щур.
} 
Задача настоящей работы - рассмотреть несколько типов контекстов употребления уж, в которых идея шкалы реализуется наиболее ярко. Возможно, если мы поймем, как работают важные компоненты смысла частицы, это приблизит нас к построению целостной картины ее функционирования.

\section{1.}

Чрезвычайно наглядно идея шкалы в значении уж проявляется в контексте специального вопроса:

(1) [neтoki, nick] И учитель абсолютно бессилен и бесправен по сути. [irga101, nick] Почему уж так бессилен? Я вот взяла да уволилась, когда мне не понравилась одна школа. [Сегодня в топе блогов история учительницы (блог) (2008)]

Как можно заметить, второй говорящий оспаривает именно степень бессилия, а не само его наличие. Первый говорящий заявляет об абсолютном бессилии, а второй возражает, что оно не абсолютно. Гораздо хуже звучал бы диалог: Учитель бессилен! - Почему уж бессилен? Он, однако, становится более естественным при наличии продолжения типа: Возможностей у учителя, конечно, мало, но какие-то рычаги все же есть, где проясняется, что второй говорящий тоже оспаривает именно степень.

В подобных случаях сочетание вопросительного слова с уж обычно сопровождается показателем высокой степени, чаще всего так:

(2) Да и перед Западом как будто непонятно становилось: отчего уж я так не оправдываюсь, ни единым словом? может, в чём-то клевета и права? [А. И. Солженицын. Бодался теленок с дубом (1967-1974)]

Как мы видим, здесь Солженицын сомневается именно в правильности такой категоричности - он говорит не о том, что зря не оправдывался, а о том, что зря не оправдывался совсем, ни единым словом.

В следующих примерах речь также идет о чрезмерности:

(3) - С мальчиком дела плохи! - угрюмо произнес Володя. - Вы же, наверное, все слышали, вам Харламов рассказывал... - Рассказывал, но я не понимаю, почему уж так плохи дела, вторичное кровотечение наступит не обязательно [Юрий Герман. Дорогой мой человек (1961)]

(4) Профессор Серебряков тоже человек. Зачем уж так презирать его? Он не гангстер, не половой психопат, он хотел жить, любил женщину, по-своему, в меру своих сил, и годами без устали занимался одним - писал, писал, писал, писал. [Юрий Трифонов. Предварительные итоги (1970)]

В первом случае говорящий считает прогноз слишком пессимистичным, во втором - отношение к чеховскому герою чрезмерно, несправедливо критическим. Фразы без так - Почему уж⿻ плохи дела, Зачем ужс презирать его - гораздо менее естественны. Конечно, такое возможно, если само по себе слово ссылается на очевидную шкалу, указывая на ее крайнюю точку: Зачем уж⿻ насмерть, Зачем ужс ненавидеть, Почему уж гениально. Но это нетипично. С другой стороны, подобные употребления уж в контексте указания на высокую степень без обозначения самого признака (часто в сочетании со словом так) как раз очень естественны:

(5) Я купил за три тыссячи долларов «бельй» военный билет <...>. Майор, военком, сказал мне, что где-то там в бумагах напишет мне косоглазие и отсутствие обеих конечностей. Когда я ужсаснулся: мол, зачем уж так?! - он резонно заметил: - Повесткой безногого не вызовешь [Виктор Слипенчук. Зинзивер (2001)]

Говорящий не против того, чтобы ему приписали болезнь, но отсутствие ног - это чересчур.

(6) - От женщины, которая таким делом занимается, может вытошнить. Ну, зачем уж так. Хорошую женщину никакое дело не испортит. [И. Грекова. На испьтаниях (1967)] 
(7) - Куличи ладно - только не вздумай их святить, не буду есть. - Да почему уж так? — < ..> - А бабушка всегда святила, и красила. Что ж это, не наша вера? [А. И. Солженицын. На изломах (1996)]

Рецензенты «Диалога» справедливо отмечают, что во всех этих случаях фигурируют исключительно вопросы о причине и цели (Почему уж, зачем уж, отчего уж, к чему уж). На самом деле другие вопросы тут тоже возможны: На что ужс тут так обижаться?; Что уж такого особенного он знает?; Сколько ужс он на нас потратил?; ср. также примеры:

(8) Надя была в полубреду. Она произносила имена Г.Шенгели и В.Нарбута с какими-то подозрениями (оказывается, и им Осип читал свое стихотворение). А кого ужс тут подозревать, если я знаю теперь 14 слушателей, а где гарантия, что их не было больше? [Эмма Герштейн. Вблизи поэта (1985-1999)]

(9) - А мне вчера исполнилось восемьдесят лет. - Поздравляю, - говорю я. Он вздыхает. - Да с чем ужс там поздравлять? - Ну хотя бы с тем, что вы до этого возраста дожили! [Владимир Войнович. Замысел (1999)]

Действительно, однако, вопросы о цели и причине в данном случае наиболее типичны. Как отметил один из рецензентов, здесь перед нами не прямые вопросы, а более сложные речевые акты - вопросы, ставящие под сомнение сказанное собеседником. Конечно, отдельно трудно себе представить фразу *Что уж ты купил? (звездочка поставлена рецензентом). Однако возможен диалог, в котором первый говорящий попрекает, что, мол, все в доме куплено им, а второй парирует: Что ужс ты такого купил? - то есть, может, что-то и купил, не так много и не такое дорогое. Вопрос Что тыл купил? подразумевает, что говорящий хочет получить перечень покупок. Вопрос Что уж ты купил? подразумевает, что говорящий оспаривает степень существенности покупок, которую собеседник, по его мнению, преувеличил. При этом фраза Что уж ты купил? - это всетаки вопрос, и на него вполне естественно услышать ответ типа: Ну не так уж и мало: вот, например, этот холодильник, да и микроволновку тоже. Этим она отличается от фраз типа Где уж мне!, которые никакого ответа не предполагают; о них речь пойдет в следующем разделе.

Здесь стоит еще обратить внимание на то, насколько разный эффект вызывает добавление разных частиц в контекст специального вопроса. Сравним уж с частицей -то (Где-то он теперь?) [Левонтина 2016]. Как будто обе частицы как-то усугубляют вопрос и притом усложняют иллокутивную цель, но совершенно по-разному. -То сообщает высказыванию функцию погружения в фантазии или воспоминания, при этом ответ от собеседника возможен, но не особенно ожидаем. Уж отчасти превращает вопрос в возражение. Естественно, что эти частицы предпочитают контексты с разными вопросительными словами, и если для уж вопросы с зачем и почему наиболее характерны, то для -то они как раз практически невозможны.

\section{2.}

Идея шкалы ярко реализуется в контексте имплицитного отрицания - например, в следующем типе контекстов уж: Какой уж тут отдых!; Куда уж мне судить об этом;

(10)Не без трепета приступаю я к написанию этого текста. Если уж Витгенштейна, по его мнению, не понял <...> сам Рассел, сумевший привести в замешательство великого Фреге, то где уюж нам. [В. А. Успенский. Витгенштейн и основания математики (2002)]

(11)Подсчитали: пахать и то нельзя на этом комбайне, где уж тут копать картошку. [Анатолий Азольский. Лопушок // «Новый Мир», 1998]

(12)Изатем, немного возвысив голос: - Исполнилось пророчество: "Не зарастёт священная тропа!.." Не зарастёт, думаю. Где уж ей, бедной, зарасти. Её давно вытоптали эскадроны туристов... [Сергей Довлатов. Заповедник (1983)]

Уж здесь факультативно: возможно и Где тут копать картошку и т. п. Уж усиливает риторический эффект, показывая, что ситуация не просто отличается от стандартной, а максимально от нее далека. 
В контекстах этого типа предпочитаются совсем другие вопросительные слова, чем в предыдущем случае, и при этом они десемантизированы: в сочетаниях где уж и куда уж отсутствует темпоральная семантика.

Уж хорошо сочетается и с эксплицитным отрицанием, причем оспаривается именно степень выраженности какой-то характеристики. В этом отношении характерно частое использование уж в составе оборота не так (уж) $u$ :

(13) Музыкой все это предприятие назвать было трудно, но <..> в жестянку, подвешенную к гармонике, монеты падали не так уж и редко... [Дина Рубина. Медная шкатулка (сборник) (2015)]

(14)Пострадавшему на всякий случай вкатили в живот семнадиать уколов от гипотетического бешенства, и все его жалели, хотя было не так уж и больно. [Алексей Варламов. Купавна // «Новый Мир», 2000]

Уж в составе этого оборота факультативно:

(15)И выстрел наконеи грохнул - не так и далеко, в сосняке. [Василь Быков. Болото (2001)]

(16)"В общем, я не так и стара", - Таня чуть не подпрыгнула от этой мысли. [Василий Аксенов. Пора, мой друг, пора (1963)]

Однако использование этой частицы в подобных контекстах чрезвычайно типично. Идея шкалы в значении частицы очень органично сочетается с ними, и нередко частица оказывается прагматически почти обязательной.

Рассмотрим сочетания: не такой уж бедный, уж не такой бедный, уж не бедный, уж и бедный. Во всех этих случаях, в том числе без слова такой, которое само по себе указывает на степень, уж указывает, что говорящей считает чрезмерной приписываемую кому-то степень бедности. Если шкала не очевидна и не введена, то высказывание с уж будет странным: 'уж не итальянский (а франиузский).

\section{3.}

В связи с ключевой для уж идеей шкалы особенно интересно обратить внимание на своеобразные эффекты сочетания уж с компаративом (чаще всего уж лучше / лучше уж и скорее уж / уж скорее, но возможно также уж правильнее / красивее / разумнее / честнее было бы и т. п. ). Сравним два диалога:

а.- Вам налить чаю? - Лучше кофе

и

b. - Вам налить чаю? - Уж лучше кофе.

Различие между ними очевидно. Репликой без частицы уж говорящий просто сообщает о своих предпочтениях, в то время как реплика Уж лучше кофе означает, что ни чай, ни кофе не соответствуют его желаниям: например, он голоден и вообще-то хотел бы поесть, или он рассчитывал, что предложат что-нибудь покрепче чая и кофе, но из двух не очень хороших вариантов второй все-таки более приемлем. Приведем еще несколько примеров:

(17) Чем так торговать, как говорится, лучше уж воровать. [Борис Екимов. Пиночет (1999)]

(18) Тут было какое-то смутное чувство, подсказывавшее, что лучше ужс я - униженный, чем я - отрёкшийся от себя. [Фазиль Искандер. Мученики сиены (1989)]

(19) - Говорят, ты стал писателем? Я растерялся. Я не был готов к такой постановке вопроса. Уэс лучше бы она спросила: "Ты гений?" Я бы ответил спокойно и положительно.. [Сергей Довлатов. Чемодан (1986)]

(20)- Тише, тише, вы всё не так делаете, вы нам только мешаете, вы уж лучше помолчите. [Владимир Войнович. Иванькиада, или рассказ о вселении писателя Войновича в новую квартиру (1976)]

Естественно, что уж хорошо сочетается и с единицами типа получше: 
(21)- Если ты сейчас же не перестанешь, я отберу у тебя ведро и отдам его другой девочке! - Хорошей? - спросила Гуля. - Да уж получше тебя, ответила мама. [Елена Ильина. Четвертая высота (1945)]

(22) Теперь стало поживописнее. Идет маленький бритый татарин какой-нибудь в чибитейке, или глупый чуваш, или разряженная мордовка. Все уж получше. [В. А. Соллогуб. Тарантас (1845)]

Говорящий не настаивает, что предлагаемый вариант хорош, но альтернативный вариант точно хуже. Та же идея реализуется и в сочетании уж не хуже:

(23)И Экссон Петролеум не смог бы без Ходорковского, который до недавнего совсем времени был прекрасным покровителем и мог разруливать пусть хуже Абрамовича, но уж не хуже Фридмана. [Сергей Доренко. Левые силь - перезагрузка (2003) // «Завтра», 2003.08.13]

(24) - Был бы у тебя брат, сам бы сейчас завтраки готовил! - Да уж не хуже бы получилось. [Юлия Лавряшина. Улитка в тарелке (2011)]

(25)- Тебе бы, Петрович, с лекииями выступать. - А что, - не смутился Елахов, - уж не хуже некоторых бы выступил. [Влада Валеева. Скорая помощь (2002)]

Напротив, в сочетании уж не лучше обсуждается хороший вариант, однако он не может быть настолько же хорош, как альтернативный:

(26)Жена вкусно готовит... Уж не лучше меня, наверное... [Ольга Новикова. Мне страшно, или Третий роман // «Звезда», 2003]

\section{4 .}

Сходная идея решения в условиях сокращенного выбора представлена в еще одном типичном для уж круге употреблений - в сочетаниях раз уж, если уж, тогда уж:

(27)Я совершенно не уверен, выйду ли я отсюда, но если ужк выйду, то плюну на всё, что я здесь пережил и видел, и забуду их, чертей, на веки вечные. [Ю. О. Домбровский. Факультет ненужных вещей, часть 2 (1978)]

(28) Если ужс говорить о сделке, то следует исходить из принципа "деньги вперёд". [Борис Дмитриев. Ни пяди назад // «Коммерсанть-Власть», 1998]

(29)Раз ужс всего напечатать нельзя, то ясно, что будет произведён отбор публикуемых произведений, - а именно только того, что хочет начальство. [И. М. Дьяконов. Книга воспоминаний (1995)]

(30)А теперь, раз уж проснулись, я вас посмотрю. Послушала сердие, измерила давление. Вполне прилично! Ничего похожего на то, что было. [И. Грекова. Перелом (1987)]

(31)Раз ужс поехали... кюгу, как ты выражаешься, надо соответственно и вести себя... Или уж сиди дома, не езди. А куда к югу-то? [Василий Шукшин. Печкилавочки (1970-1972)]

(32) Он сказал: - Тогда я сделаю вот что. Я тебя поцелую. - И это лишнее, возразил Краснопёров. Забулдыга постоял в раздумье. Затем взглянул на Красноперова и твёрдо произнёс: — Тогда ужс я как минимум — спою. [Сергей Довлатов. Иная жизнь (1984)]

(33)Раз ужс заговорил про Ленинград, стоит вспомнить забавный эпизод, связанный с одним из моих самых любимых драматических актёров. [И. Э. Кио. Иллюзии без иллюзий (1995-1999)]

(34)Понимаете? Наберите ещее раз. А если опять никто не отвечает... - Ну тогда ужс прямиком в милицию, - пообешал я [Андрей Волос. Недвижсимость (2000) // «Hовыцй Мup», 2001]

В контекстах сокращенного выбора реализуется та идея, которую Д. Пайар считает центральной для значения уж, - идея необсуждаемого. Выбор производится из ограниченного круга возможностей, остальные исключены из рассмотрения. Здесь важно обратить внимание, что ужс уместно в контекстах сокращенного выбора вовсе не всегда. Когда сокращение выбора не 
приводит к увеличению возможностей, уж не используется. Например, один человек просит другого заехать куда-либо по дороге. Сравним два возможных ответа. В первом случае собеседник отвечает:

(35)а. Я не знаю, буду ли завтра выезжать, но если уюс буду, то, конечно, заеду.

Здесь задается некая шкала затрат времени и сил, и уж очень естественно. Ср., однако, другой ответ:

b.??я не знаю, буду ли завтра выезжать, но если уж буду, то вообще в другую сторону.

Это очень странная фраза, здесь уместна была бы не частица уж, а частица даже, поскольку в данном случае возможная поездка никак не продвигает ситуацию в направлении возможности выполнения просьбы. Шкала не выстраивается, и уж оказывается неуместным.

Вообще использование дискурсивных слов в условных, причинных, уступительных контекстах всегда сопряжено с невероятно разнообразными семантическими и прагматическими эффектами; об этом есть большая литература, см., например, [König 1991]. Стоит также отметить, что что в поведении уж в подобных контекстах обнаруживается сходство с другим дискурсивным словом - хоть. В знаменитой работе П. Паршина [Паршин 1988] семантика хоть описывается через понятие деонтического диалога. Хоть является средством переговоров, торга в широком смысле и дает совершенно разные эффекты в зависимости от роли говорящего (проситель или контролер) и от характера сценария (позитивного или негативного): - Дай хоть рубль! - Хоть десять, мне не жалко! / - Хоть копейку, ничего не дам. Хоть и уж - слова со скалярной семантикой, приспособленные для такого рода торга, и механизмы образования прагматических эффектов у них довольно похожи. Ср. - Позволь уж⿻ мне попробовать! - Ладно уж⿻! / - Нет уж⿻, ни за что.

\section{5 .}

В споре уж часто выражает идею, что говорящий готов был бы пойти на уступки, но не до такой степени - как в знаменитом стихотворении Д. Хармса «Врун» (1930):

(36) - А вы знаете, что У?

А вы знаете, что ПА?

A вы знаете, что ПЬІ?

Что у папы моего

Было сорок сыновей?

Было сорок здоровенных -

И не двадиать,

И не тридиать,-

Ровно сорок сыновей!

— Hy! Hy! Hy! Hy!

Bрешь! Врешь! Врешь! Врешь!

Eщзе двадиать,

Еще тридиать,

Ну еше туда-сюда,

А уюж сорок,

Ровно сорок, -

Это просто ерунда!

Интересно, что здесь в паре с уж выступает еще: тридцать еще туда-сюда, а уж сорок - никак. Идея шкалы видна очень наглядно. Обе частицы могут присоединяться как к теме, так и к реме - и даже, как еще в этом примере - и к теме, и к реме (Еще тридиать - еще туда сюда). Здесь сказано Уж сорок - это ерунда, но возможно и Сорок - это уж ерунда.

Именно обыгрывание идеи шкалы является в этом стихотворении одним из основных источников комизма. Если в первой итерации числа 20-30-40 действительно задают шкалу, то в других непонятно, почему одно менее правдоподобно, чем другое:

Что на небе

Вместо солнияа 
Скоро будет колесо?

Скоро будет золотое -

Не тарелка,

Не лепешка, -

А большое колесо!

$$
\begin{aligned}
& <\ldots .> \\
& \text { Что под морем-океаном } \\
& \text { Часовой стоит с ружьм? } \\
& <\ldots> \\
& \text { Ну, с дубинкой, } \\
& \text { Ну, с метелкой, } \\
& \text { Ну еще туда-сюда, } \\
& \text { А с заряженньм ружьем- } \\
& \text { Это просто ерунда! }
\end{aligned}
$$

Конечно, тарелка или лепешка в качестве заменителя солнца ничем не лучше и не хуже колеса, а часовой с ружьем может стоять под морем с тем же успехом, что часовой с метелкой. Однако использованная частица навязывает представление о шкале правдоподобия. Эта шкала совершенно фантастична, и при этом она задана имплицитно и подается как нечто само собой разумеющееся. За счет высокой степени суггестивности и создается это ощущение невероятного абсурда ${ }^{3}$.

В подобных контекстах уж часто фигурирует в сочетании с другими частицами: ну, прям, да, и, так:

(37)Как - есть чувство, что вы немного отеи этим ребятам?» - «Немного есть», - уныло соглашался Владимир. - Да ужк, - не верила Ася. - Уж прям ужс. - Что вы все такие ядовитые? - вдруг яростно схватывалась Таня [Ирина Полянская. Сельва (1996)]

(38)Везет же тебе... Мой и не ездит и прав не имеет и к машине только чтобы сесть рядом подходит... Будущая жена. Везет же тебе... Да уж прям. [Учимся водить (2007-2008)] [

(39) Тебе-то, молодому, еще все нипочем, а товарищ генерал у вас - пожилье, им бы поберечься. - Ну, уж и пожилье, - обиделся генерал слегка игриво. - Я еще таких молодых двоих заменю [Г. Н. Владимов. Генерал и его армия (1994)]

(40) - Как это благородно с вашей стороны, несмотря на ночь, не отказаться от визита, - сказал он с ледяной учтивостью. - Да ради рюмки он и до Москвы доползет, - сказала Адель и указала лекарю на дверь. - Ну уж и ради рюмки, - обиделся Иванов. [Булат Окуджава. Путешествие дилетантов (Из записок отставного поручика Амирана Амилахвари) (1971-1977)]

\footnotetext{
3 Другой источник комического в этом стихотворении тоже имеет лингвистическую природу. В последней части говорится:

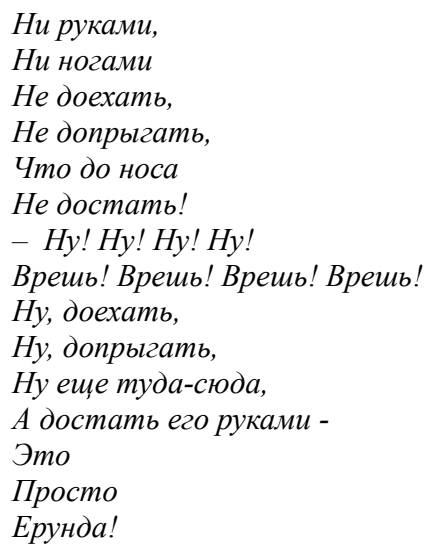

Здесь обыгрывается омонимичность фразы Это просто ерунда. Во всех фрагментах она означает 'Это бессмысленно', а в последней - ‘Это очень легко'.
} 
(41)- Ну ужс и обрадуются, - сказал Соколов. - Так же, как спортсмены радуются, когда не они, а кто-нибудь другой устанавливает рекорд. [Василий Гроссман. Жизнь и судьба, часть 2 (1960)]

(42) - Ну, может быть, там какие-нибудь деликатные женские подробности, шутливо нахмурился прокурор.- Вот всё вам так ужк и выложить! [Ю. О. Домбровский. Факультет ненужных вещей, часть 4 (1978)]

Возможны даже самостоятельные реплики Ну уж! Уж прям! и. п., выражающие реакцию на реплику, которая кажется слишком неправдоподобной.

\section{2.}

Наличие в значении модального уж компонентов 'шкала' и 'превышение ожиданий' совершенно естественно: они связаны с тем временным значением уж, в котором оно близко к временно́му уже и указывает на опережение. Развитие у временно́го слова модального значения, при котором происходит трансформация временно́й шкалы в шкалу ожиданий или возможностей, вполне типично. Об этом применительно к значению частиц уже и уж см. [Урысон 2007; 536360]. Ср. следующий пример, в котором невозможно различить временную шкалу и шкалу ожиданий:

(43) Мы, не помню ужс зачем, приехали в Сталинабад, и по пути обратно в горы заехали на ГАЗ-51 на рынок. [Александр Городнищкий. «И жить еще надежде» (2001)]

Не помню ужс - значит 'раньше помнил, но за давностью лет забыл' или 'не помню, да это и несущественно'?

Итак, мы рассмотрели, как семантический компонент 'шкала' реализуется в некоторых типах контекстов уж. Как следует поступать дальше - включать ли этот компонент в инвариантное описание уж или в толкование только отдельных значений (лексем) этой частицы - зависит от идеологии описания.

Разумеется, упомянутыми выше семантическими компонентами значение уж не исчерпывается. Так, важнейший элемент этой смысла частицы составляет идея объяснения, ссылки на чтото, влияющее на итоговую оценку ситуации говорящим (фраза Уж очень умный не может быть сказана просто при описании человека - она уместна, если говорящий объясняет, почему этот человек ему нравится/подходит или, напротив, не годится $)^{4}$. При этом говорящий считает объяснение достаточным, не требующим дальнейшего обсуждения (Так уж здесь принято), часто даже блокирующим его; ср. контексты типа Не знаю уж, как они познакомились..., где уж ясно указывает, что говорящий не имеет в виду обсуждать знакомство, а хочет обсудить что-то, что было потом. С этим компонентом смысла также связаны разнообразные семантические и прагматические эффекты, которые мы не можем проанализировать в небольшой статье.

Пожалуй, общую идею частицы уж можно описать примерно так: уж указывает на то, что ситуация отклоняется от нормы или ожиданий говорящего/слушающего в такой степени (большой или маленькой), что ссылка на это полностью объясняет итоговую оценку говорящим ситуации. Однако, чтобы подробно показать, как этот смысл взаимодействует с разными типами контекстов, нужна была бы целая книга.

\section{Acknowledgements}

Работа выполнена при поддержке РФФИ, грант 19-012-00291.

\footnotetext{
4 Этот компонент смысла подробно описан применительно к противительным и уступительным словам.
} 


\section{References}

[1] Levontina 2008 - Levontina I. B. Zagadki chasticy uzh [Riddles of the particle uzh] // Komp'yuternaya lingvistika i intellektual'nye tekhnologii. Po materialam ezhegodnoj Mezhdunarodnoj konferencii «Dialog» (Bekasovo, 4-8 iyunya 2008 g.). Vyp. 7(14). M., 2008.

[2] Levontina 2016 - Levontina I. B. O nekotoryh maloizuchennyh upotrebleniyah chasticy -to [On some poorly studied uses of the particle -to] // Yazyk: poiski, fakty, gipotezy: Sbornik statej k 100-letiyu so dnya rozhdeniya akademika N. Yu. Shvedovoj / Otv. red. M. V. Lyapon. - M.: LEKSRUS, 2016. - 816 s. S. 359-375.

[3] Morkovkin 1997 - Morkovkin V. V. (red.). Slovar' strukturnyh slov russkogo yazyka [Dictionary of structural words of the Russian language]. M., 1997.

[4] Parshin 1988. Parshin P.B. Ustupka i antiustupka v deonticheskom dialoge (funkcionirovanie leksemy hot') [Concession and anti-concession in the deontic dialogue (functioning of the lexeme xot')] // Referenciya i problemy tekstoobrazovaniya. Moskva: Problemnaya gruppa \"Logicheskij analiz yazykal", 1988. S. 146-168.

[5] Uryson 2007 - Uryson E. V. Uzhe i uzh: variativnost', polisemiya, omonimiya? [Uzhe and uzh: variability, polysemy, homonymy?] // Komp'yuternaya lingvistika i intellektual'nye tekhnologii. Trudy mezhdunarodnoj konferencii «Dialog» (Bekasovo, 30 maya - 3 iyunya 2007 g.) M., 2007. S. 531-541.

[6] Shimchuk, Shchur 1999 - Shimchuk E. G., Shchur M. G. Slovar' russkih chastic. [Dictionary of Russian Particles]. Frankfurt am Main, 1999.

[7] König 1991. König, E. The Meaning of Focus Particles. A Comparative Perspective. London: Routledge 1991.

[8] Mendoza 1999 - Mendoza I. Uzhe und uzh in der modernen russischen Standardsprache // Die Welt der Slaven. 1999. No. 44(2). S. 213-224.

[9] Mendoza 2000 - Mendoza I. Zur Geschichte von Partikeln: russisch uzhe und uzh // Linguistik online. 2000. No. 2.

[10] Paillard 1986-1987 — Paillard D. Už ou l'indiscutable // Bulletin de linguistique appliquée et générale. 1986/87. No. 13. P. 190-213.

[11] Zybatow 1990 - Zybatow L. Was die Partikeln bedeuten. Eine kontrastive Analyse Russisch-Deutsch. München, 1990. 